Note

\title{
Antihypertensive Effects of Nicotianamine from Soybean Broth in Spontaneously
}

\section{Hypertensive Rats}

\author{
Tetsuo TAKenaka $^{1^{*}}$, Takashi Murayama ${ }^{1}$, Tadasu Furusho ${ }^{2}$ and Yoko Takenaka ${ }^{3}$ \\ ${ }^{1}$ Faculty of Agriculture, Tamagawa University, 6-1-1,Tamgawa-gakuen,Machida, Tokyo 194-8610, Japan \\ ${ }^{2}$ Department of Nutrition, Jr. College of Tokyo University of Agriculture, 1-1-1 Sakuragaoka, Setagaya-ku, Tokyo 156-8502, Japan \\ ${ }^{3}$ T\&T Food Institute, 555-20 Aina, Astugi, Kanagawa 243-0038, Japan
}

Received December 1, 2008; Accepted May 11, 2009

The effect of the ACE inhibitor nicotianamine (NA), from soybean broth (SB), on blood pressure was investigated in spontaneously hypertensive rats (SHR) upon single and long-term administration. The $\mathrm{IC}_{50}$ value of NA from SB was $0.69 \mu \mathrm{mol} / \mathrm{L}$. Single oral dose of NA $(0.9 \mathrm{mg}, 4.5 \mathrm{mg}$ and $9.0 \mathrm{mg} / \mathrm{kg} \mathrm{body}$ weight) decreased blood pressure $1 \mathrm{~h}$ after administration, and blood pressure returned to the control level $3 \mathrm{~h}$ after administration. Long-term oral dose of NA ( $0.9 \mathrm{mg}$ and $4.5 \mathrm{mg} / \mathrm{kg}$ body weight) decreased blood pressure for 4 weeks after administration, while that of NA $(9.0 \mathrm{mg} / \mathrm{kg}$ body weight $)$ was decreased for the full 8-weeks feeding period. At 8 weeks after administration, serum NA content in SHR was determined by amino acid analyzer and revealed that NA was not detected in the blood of SHR (0.9 $\mathrm{mg}$ and 4.5 $\mathrm{mg} / \mathrm{kg}$ body weight group), while $32.6 \pm 7.3 \mu \mathrm{g} / \mathrm{dL}$ NA was detected in the $9.0 \mathrm{mg} / \mathrm{kg}$ body weight group. It was suggested that NA absorbed from the intestine decreased the systolic blood pressure (SBP) in SHR, and an appropriate NA level $(9.0 \mathrm{mg} / \mathrm{kg}$ body weight group) may provide long-term antihypertensive effects upon administration.

Keywords: ACE inhibitor, antihypertensive factor, nicotianamine, soybean broth (SB), spontaneously hypertensive rats (SHR), angiotensin system

\section{Introduction}

The miso, soysauce and natto manufacturing processes produce large amounts of spent residue (soybean broth (SB)) as a waste by-product, and its disposal poses severe environmental challenges. SB contains a large amount of proteins and water-soluble polysaccharides and has a high COD (chemical oxygen demand) value, on average about 20,000 ppm, resulting in high waste-water treatment costs. The food industry's utilization of SB as a food material is still in the developmental stage. The effective utilization of SB (Matsuda and Ueda, 1995; Kimura et al., 1997), such as the production of flavorful vinegar by fermentation (Morimura et al., 2005) and the production of GABA by lactic acid bacteria (Furuta et al., 2008), has been reported. We have already reported a method by which the ACE inhibitor nicotianamine is easily

*To whom correspondence should be addressed. E-mail: takenaka@agr.tamagawa.ac.jp separated from SB (Takenaka et al., 2009).

The angiotensin I-converting enzyme (ACE; EC3.4.15.1) catalyzes the hydrolysis of angiotensin I to generate the potent vasoconstrictor, angiotensin II. This enzyme plays an important role in the renin-angiotensin system to regulate both arterial blood pressure, and salt and water balance. ACE inhibitors, such as captopril and enalapril, have been used as antihypertensive drugs (Gray et al., 1995).

In recent years, many ACE inhibitory peptides have been isolated from food protein sources such as casein (Maruyama et al., 1982), tuna (Kohama et al., 1988) and bonito (Matsui et al., 1993). There have been several reports about the nonpeptidyl ACE inhibitors polyphenol (Horie et al., 1996) and nicotianamine (Kinoshita et al., 1993; Shimizu et al., 1999; Hayashi et al. 2005).

In this paper, we investigated the influence of nicotianamine on SBP in SHR upon single and long-term administration. 


\section{Materials and Methods}

Experimental animals and measurement of blood pressure Male SHR (11 weeks old) were purchased from Charles River Japan, and were maintained under the following conditions: temperature, $23 \pm 1{ }^{\circ} \mathrm{C}$; relative humidity 55 $\pm 5 \%$; $12 \mathrm{~h}$ light/dark cycle. All animals were allowed a standard diet (AIN-76, Oriental Yeast Industry, Tokyo, Japan) and tap water. The systolic blood pressure (SBP) was measured using a tail-cuff with a SBP monitor for rats and mice, Model NK-2000 (Muromachi Kikai Ltd., Tokyo). All the animal experiments were conducted in compliance with the guidelines of the Japanese Association for Laboratory Animal Science (1987) and guidelines for Animal Experiments of the Research and Development Division of Tamagawa University.

Materials Soybean broth (SB), a by-product of the Natto manufacturing process, was obtained from Oyama Tofu Co. (Japan) and contained protein (8.9\%), fat (3.2\%), carbohydrate (77.2\%), ash (10.6\%) per dry weight. ACE from rabbit lung acetone powder was obtained from Sigma Chemical Co. (USA).

Hippuryl-L-histidyl-L-Leucine (Hip-His-Leu) was obtained from the Peptide Institute (Osaka, Japan). Amberlite IR-120 was obtained from Rohm \& Hass Co (USA). Sephadex G-15 was obtained from GE healthcare (USA). The nicotianamine standard was kindly supplied by Dr. Kinoshita of Kikkoman Co. (Japan).

Assay of ACE inhibitory activity ACE inhibitory activity was assayed by a modified method of Cushman and Cheung (1971). The reaction mixture was as follows: 250 $\mu 1$ of $12.2 \mathrm{mM}$ Hip-His-Leu and $608 \mathrm{mM} \mathrm{NaCl}$ in $130 \mathrm{mM}$ borate buffer ( $\mathrm{pH} 8.3$ ), $30 \mu \mathrm{l}$ of water or inhibitor, $100 \mu \mathrm{l}$ of ACE solution (obtained from $0.5 \mathrm{~g}$ rabbit lung acetone powder dissolved in $5.0 \mathrm{ml}$ of the same borate buffer, centrifuged for $10 \mathrm{~min}$ at $1500 \times \mathrm{g}$, and the upper layer was removed. After incubation at $37^{\circ} \mathrm{C}$ for 1 hour, the reaction was stopped by adding $250 \mu \mathrm{l}$ of $1 \mathrm{M} \mathrm{HCl}$. The hippuric acid released was extracted with $2.0 \mathrm{ml}$ of ethyl acetate.

After centrifugation for $10 \mathrm{~min}$ at $1500 \times \mathrm{g}, 1 \mathrm{ml}$ of the upper layer was dried using an evaporator. The residue was dissolved in $3 \mathrm{ml}$ of distilled water, and the absorbance was measured at $228 \mathrm{~nm}$. The inhibitory activity was calculated by the following formula: Inhibition activity $(\%)=($ Control - Sample) $/$ (Control - Blank $) \times 100$. The concentration of ACE inhibitors needed to inhibit $50 \%$ of ACE activity was defined as the IC50 value under these conditions.

Quantitative analysis of nicotianamine Concentrations of the ACE inhibitor nicotianamine in SB and serum were determined by an amino acid analyzer (JEOL JLC-500/V).

Preparation of the ACE inhibitor from $S B$ The ACE in- hibitor was prepared by a previously described method (Takenaka et al., 2009).

Nicotianamine was isolated from SB using an ionexchange column, Amberlite IR-120-B and Sephadex G-15 chromatography. Briefly, $300 \mathrm{~g}$ (dry weight) of SB was dissolved in $3 \mathrm{~L}$ of distilled water and centrifuged for $10 \mathrm{~min}$ at $1500 \times \mathrm{g}$. The supernatant was applied to an Amberlite IR120-B column previously prepared as $\mathrm{H}^{+}$type and then eluted with $2.7 \mathrm{M} \mathrm{NH}_{4} \mathrm{OH}$. The $\mathrm{NH}_{4} \mathrm{OH}$ in the eluate was evaporated to dryness. The ACE inhibitor fraction from the Amberlite IR120-B column was then gel-filtered on the Sephadex G-15 column, previously equilibrated with $50 \mathrm{mM}$ acetic acid, and then eluted with $50 \mathrm{mM}$ acetic acid. The ACE inhibitor active fractions were pooled and lyophilized. Identification of the ACE inhibitor from SB was carried out on the IR, NMR and TOF-mass spectrometer. The ACE inhibitor active fraction was used for single and long-term administration.

Single NA administration After preliminary breeding, 20-weeks-old male SHR were divided into four dietary groups of 6 rats each. Nicotianamine $(0.9,4.5$ and $9.0 \mathrm{mg} / \mathrm{kg}$ body weight; abbreviated as follows: $0.9,4.5$ and $9.0 \mathrm{mg} / \mathrm{kg}$ groups) dissolved in saline was orally administered to SHR (3 groups), and control rats were administered an identical volume of physiological saline alone. SBP was measured every alternate hour for $5 \mathrm{~h}$ after ACE inhibitor administration.

Long-term NA administration After preliminary breeding, 22-weeks-old male SHR were divided into four dietary groups of 6 rats each. As shown in Table 1, the test diets contained $0.002 \%, 0.010 \%$ and $0.020 \%$ of the ACE inhibitor nicotianamine were prepared by altering the proportion of or-

Table 1. Composition of experimental diets.

\begin{tabular}{|c|c|c|c|c|}
\hline \multirow{2}{*}{$\begin{array}{l}\text { nicotianamine } \\
\text { content }\end{array}$} & \multirow[t]{2}{*}{ Control } & 0.9 & 4.5 & 9.0 \\
\hline & & \multicolumn{3}{|c|}{ (mg/kg body weight) } \\
\hline & \multicolumn{4}{|c|}{$(\mathrm{g} / \mathrm{kg})$} \\
\hline Corn starch & \multicolumn{4}{|c|}{397.5} \\
\hline Casein & \multicolumn{4}{|c|}{200.0} \\
\hline Dextrized corn starch & \multicolumn{4}{|c|}{132.0} \\
\hline Cellulose & \multicolumn{4}{|c|}{50.0} \\
\hline Soybean oil & \multicolumn{4}{|c|}{70.0} \\
\hline Vitamine mix (AIN76) & \multicolumn{4}{|c|}{10.0} \\
\hline Mineral mix (AIN76) & \multicolumn{4}{|c|}{35.0} \\
\hline L-Cystine & \multicolumn{4}{|c|}{3.0} \\
\hline Choline bitartrate & \multicolumn{4}{|c|}{2.5} \\
\hline \multirow{2}{*}{$\begin{array}{c}\text { sucrose } \\
\text { nicotianamine }(\mathrm{mg})\end{array}$} & 100.0 & 99.98 & 99.9 & 99.8 \\
\hline & 0.0 & 20.0 & 100.0 & 200.0 \\
\hline
\end{tabular}

AIN76-MX; Oriental Yeast Co., Tokyo, Japan AIN76-VX; Oriental Yeast Co., Tokyo, Japan 
dinary sucrose content. Nicotianamine was added to AIN-76 diet in amounts that corresponded to the administration of 0.9 , 4.5 and $9.0 \mathrm{mg} / \mathrm{kg}$ body weight. The test diets were given to SHR for 8 weeks and after withdrawal from the test diet treatment for an additional 2 weeks.

SBP was measured weekly and body weight was measured daily. Blood was collected from SHR at 8 weeks after administration of test diets and at 2 weeks after the withdrawal from the test diets. All serum samples were kept frozen at $-40^{\circ} \mathrm{C}$ until assayed.

Statistical analysis The statistical analysis was performed using STATCEL2 statistical software. One-factor ANOVA followed by Tukey's test (Yanai, 2004) was used to evaluate the significance of differences among the groups. The experimental data are shown as the means \pm S.E.M. Differences were considered to be statistically significant at $P<$ 0.05 .

\section{Results and Discussion}

$A C E$ inhibitor concentration in $S B$ The amount of nicotianamine in SB was $2.2 \mathrm{mg} / \mathrm{g}$ dry weight as determined by amino acid analyzer. The $\mathrm{IC}_{50}$ value of nicotianamine from $\mathrm{SB}$, as determined using rabbit lung enzyme with HHL as the substrate, was $0.21 \mu \mathrm{g} / \mathrm{ml}(0.69 \mu \mathrm{M})$.

Influence of nicotianamine administration on weight of rats The average body weights did not differ between groups. The average food intake and water consumption, ratios of organ weights, and SHR serum lipid levels did not differ between groups (data not shown).

Effects of single administration of nicotianamine on SBP in SHR The effects of single administration of nicotianamine on SBP in SHR are shown in Fig. 1. SBP was measured at every alternate hour after administration of test diets. The SBP was significantly lower $1 \mathrm{~h}$ after administration of nicotianamine ( $4.5 \mathrm{mg}$ and $9.0 \mathrm{mg} / \mathrm{kg}$ body weight) compared to control, and returned to the control level $3 \mathrm{~h}$ after administration.

Kinoshita et al. (1993) reported that the HW fraction, containing nicotianamine, from soy sauce reduced SPB in SHR after oral administration. SBP was significantly decreased by $21 \mathrm{mmHg}(p<0.05)$ as compared to the control group $8 \mathrm{~h}$ after SHR were administered purified nicotianamine $(100.0 \mathrm{mg} / \mathrm{kg}$ body weight), and returned to the control level at $24 \mathrm{~h}$. There is a large difference in the SBP change in SHR reported by Kinoshita and our results. The dose of nicotianamine administered in our animal experiment corresponds to about $1 / 10$ or less than that reported by Kinoshita et al. (1993). The existence of variation in the effective level of NA among these results remains to be clarified.

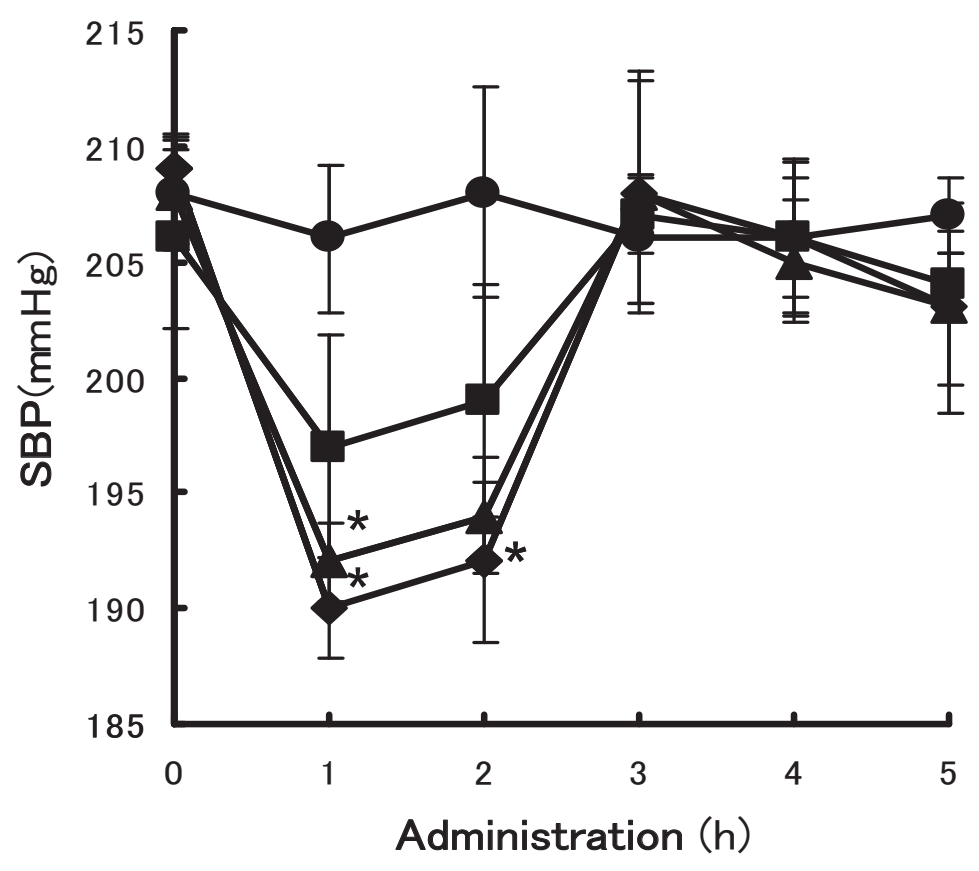

Fig. 1. Effects of single administration of nicotianamine on SBP in SHR.

Symbols: 0 : control (saline at a dose of $5.0 \mathrm{ml} / \mathrm{kg}$ body weight); $\mathbf{\square}: 0.9 \mathrm{mg} / \mathrm{kg}$ group (nicotianamine at a dose of $0.9 \mathrm{mg} / \mathrm{kg}$ body weight); $\boldsymbol{\Delta}: 4.5 \mathrm{mg} / \mathrm{kg}$ group (nicotianamine at a dose of $4.5 \mathrm{mg} / \mathrm{kg}$ body weight); $\$ 9.0 \mathrm{mg} / \mathrm{kg}$ group (nicotianamine at a dose of $9.0 \mathrm{mg} / \mathrm{kg}$ body weight). Each value is expressed as mean \pm S.E.M. $(n=6)$. Significant difference from the control group: ${ }^{*} P<0.05$. 
Effects of long-term administration of nicotianamine on SBP in SHR The composition of test diets used for longterm administration is shown in Table 1. The SBP of the 0.9, 4.5 and $9.0 \mathrm{mg} / \mathrm{kg}$ groups were significantly lower than in the control for 2-4 weeks after NA administration initiation (Fig. 2). Subsequently, SBP levels of the 0.9 and $4.5 \mathrm{mg} / \mathrm{kg}$ groups gradually returned to the control level 6 to 8 weeks after administration initiation. However, the SBP of the $9.0 \mathrm{mg} / \mathrm{kg}$ group was significantly lower than in the control, $23.4 \pm 3.4$ $\mathrm{mmHg}(p<0.05)$ decrease, for 8 weeks of the test feeding period. Although a sufficient antihypertensive effect was not shown at a dose of $9.0 \mathrm{mg} / \mathrm{kg}$ body weight upon single administration, an antihypertensive effect was seen upon long administration of the identical dose.

Shimizu et al. (1999) reported on the effects of longterm administration of the $G$ fraction (containing NA) from Ashitaba and captopril on SHR. The SBP of G fraction (21.8 $\mathrm{mg} / \mathrm{kg}$ body weight)- and captopril ( $0.3 \mathrm{mg} / \mathrm{kg}$ body weight)treated groups were $200 \pm 7.3 \mathrm{~mm} \mathrm{Hg}(\mathrm{n}=7)$ and $198 \pm 8.1$ $\mathrm{mmHg}(\mathrm{n}=5)$ at the end of 10 weeks of administration, respectively. The SBP of the control group was $211 \pm 3.7$ $\mathrm{mmHg}(\mathrm{n}=7)$. The content of NA in the $\mathrm{G}$ fraction remains to be clarified.

The reversal of an antihypertensive effect in the $0.9 \mathrm{mg}$ and $4.5 \mathrm{mg} / \mathrm{kg}$ groups may be a result of the low ACE inhibitor affinity for vascular tissue and the high ACE inducing ability of the vascular tissue (Miyazaki, 1995). The serum nicotianamine concentration was measured using an amino acid analyzer to assess the distribution of administered nicotianamine at 8 weeks after administration and 2 weeks after withdrawal from test diet. Chromatograms of nicotianamine in serum from control diet and test diet groups at 8 weeks after administration are shown in Fig. 3. Nicotianamine was not detected in the serum of the $0.9 \mathrm{mg} / \mathrm{kg}$ and $4.5 \mathrm{mg} / \mathrm{kg}$ groups, while it was detected $(32.6 \pm 7.3 \mu \mathrm{g} / \mathrm{dL} ; \mathrm{n}=6)$ in the serum of the $9.0 \mathrm{mg} / \mathrm{kg}$ group. Nicotianamine was not detected in the serum at 2 weeks after the withdrawal from test diet. Hayashi et al. (2005) reported that after nicotianamine was administered into the stomach of Tsukuba hypertensive mice (THM), it was absorbed from the intestine and into the blood, and consequently, the absorbed nicotianamine decreased SBP and ACE activity in the plasma. It was thought that a similar distribution of nicotianamine had been carried out in SHR, although serum ACE activity was not measured in our experiment. We are currently conducting further experiments to clarify the ACE activity and concentration of nicotianamine in the serum of SHR upon long-term administration.

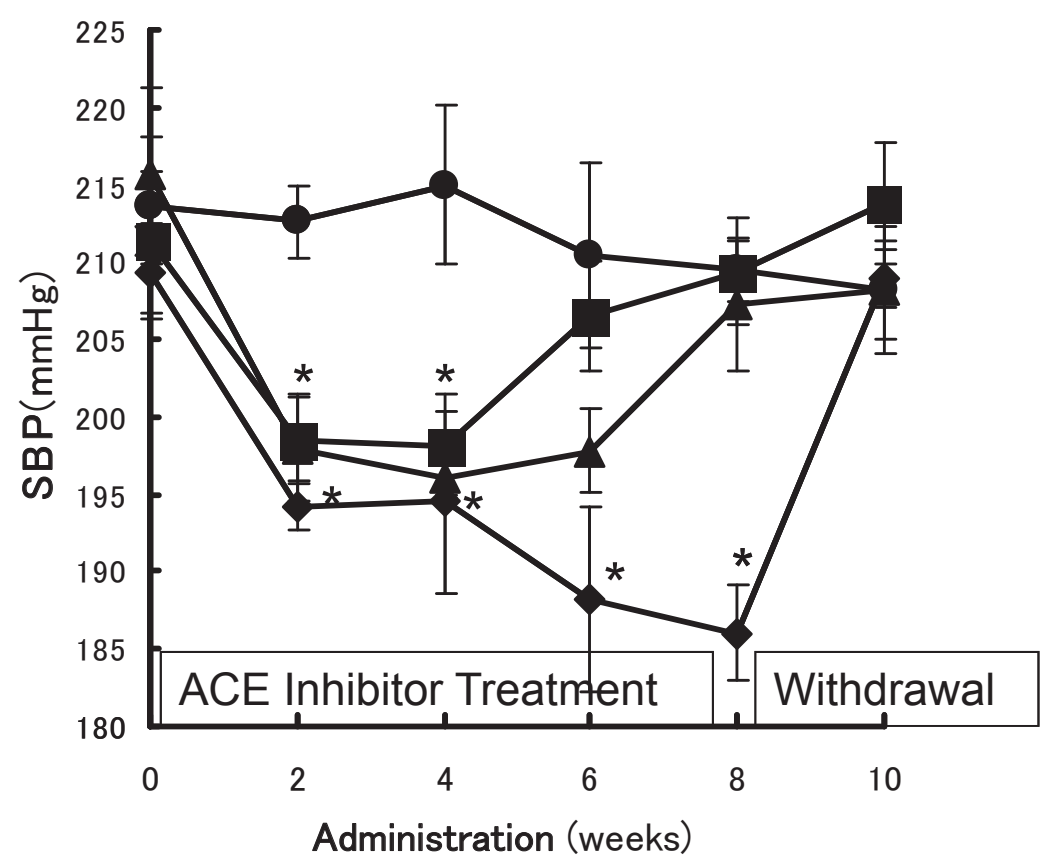

Fig. 2. Effects of long-term administration of nicotianamine on SBP in SHR. Symbols: O: control (nicotianamine at a dose of $0.0 \mathrm{mg} / \mathrm{kg}$ body weight); $\mathbf{\square}: 0.9 \mathrm{mg} / \mathrm{kg}$ group (nicotianamine at a dose of $0.9 \mathrm{mg} / \mathrm{kg}$ body weight); $\mathbf{\Delta}: 4.5 \mathrm{mg} / \mathrm{kg}$ group (nicotianamine at a dose of 4.5 $\mathrm{mg} / \mathrm{kg}$ body weight); $: 9.0 \mathrm{mg} / \mathrm{kg}$ group (nicotianamine at a dose of $9.0 \mathrm{mg} / \mathrm{kg}$ body weight). The test diet was administered for 8 weeks and its withdrawal for an additional 2 weeks. Each value is expressed as mean \pm S.E.M $(\mathrm{n}=6)$. Significant difference from the control group: ${ }^{*} P<0.05$. 

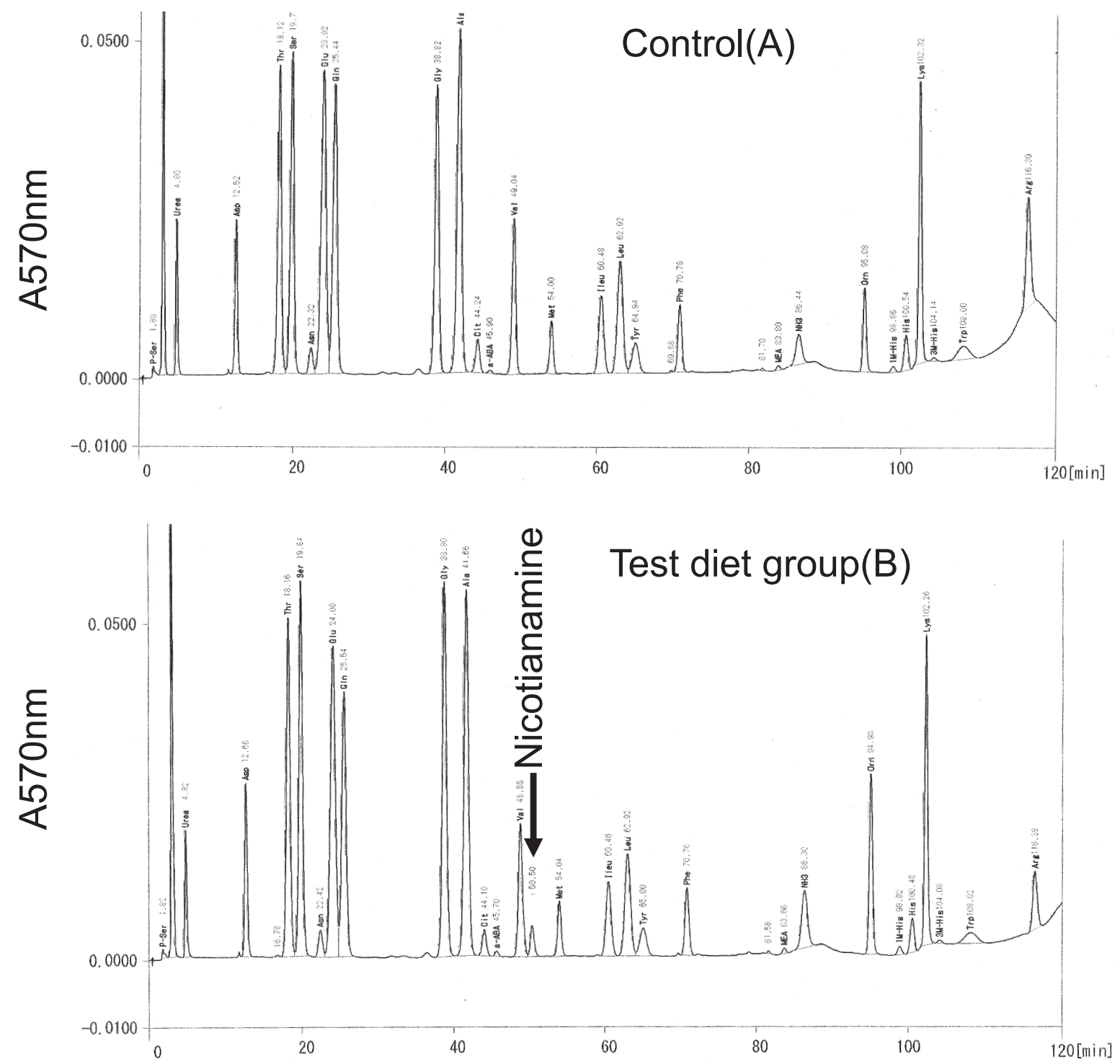

Fig. 3. Chromatograms of serum nicotianamine levels in control diet and test diet groups at 8 weeks after administration. Nicotianamine was measured by amino acid analyzer. Chromatogram of SHR serum in control (A) and test diet group (B) at 8 weeks after administration.

\section{References}

Cushman, W. D. and Cheung, S.H. (1971). Spectrophotometric assay and properties of the angiotensin I-converting enzyme of rabbit lung. Biochem. Pharmacol., 20, 1637-1648.

Furuta, M., Kuroda, R., Tsukatani, T., Higuchi, T., Hirofuji, Y., Miyagawa, H., Muta, S. and Suzaki, O. (2008). Production of $\gamma$-amino butyric acid by lactic bacteria in soybean broth. Nippon Shokuhin Kagaku Kogaku Kaishi, 55, 299-303 (in Japanese).

Gray, A.F., French, F.J. and Dage, C.R. (1995). Dual inhibitors of ACE and neutral endopeptidase. In: Hypertensions (Laragh, J.H., Breenner, B.M., eds), 2nd, Raven Press, N.Y. pp.3099-3112.

Hayashi, A., Nakayama, T., Murakami, K., Aoyagi, Y. and Kimoto, K. (2005). Effects of Nicotianamine on blood pressure in Tsukuba hypertensive mice (THM). J. Jpn. Soc. Nutr. Food Sci., 58,
315-331.

Hori, H., Goto, T. and Kohata, K. (1996). Comparison of inhibitory activity of angiotensin I-converting enzyme among various kinds of teas. Bull. Tea. Proc. Technol., 9, 37-40.

Kimura, I., Matsubara, Y. and Shibasaki, H. (1997). Utilization of waste water from Soy-bean cooking. Nippon Jyozo Kyokaishi, 92, 478-485 (in Japanese).

Kinoshita, E., Yamakoshi, J. and Kikuchi, M. (1993). Purification and identification of an angiotensin I-converting enzyme inhibitor from soy sauce. Biosci. Biotechnol. Biochem., 57,1107-1110.

Kohama, Y., Matsumoto. S., Oka, H., Teramoto, T., Okabe, M. and Mimura, T. (1988). Isolation of angiotensin I-converting enzyme inhibitor from tuna muscle. Biochem. Biophys. Res. Commun., 155, 322-337. 
Maruyama, S. and Suzuki, H. (1982). A peptide inhibitor of angiotensin I-converting enzyme in the tryptic hydrolysate of casein. Agric. Biol. Chem., 46, 1393-1394.

Matsuda, S. and Ueda, S. (1995). Utilization of Soybean Cooked Syrup and Changes in Composition by Lactic Acid Bacteria. Nippon Jyozo Kyokaishi, 90, 592-596 (in Japanese).

Matsui, T., Matsufuji, H., Seki, E., Osajima, K., Nakashima, M. and Osajima, Y. (1993). Inhibition of angiotensin I-converting enzyme. Biosci. Biotechnol. Biochem., 57, 922-925.

Miyazaki, M., Kawamoto, T. and Okunishi, H. (1995) Vascular affinity of trandolapril. Am. J. Hypertens, 8, s63-s67.

Morimura, S., Inagaki, S., Umezaki, M., Shigematsu, T. and Kida, K. (2005). Production of vinegar from boiled soybean extract and evaluation of its physiological activities in vitro. Nippon shokuhin Kagaku Kogaku Kaishi, 52, 578-583 (in Japanese).

Shimizu, E., Hayashi, A., Takahashi, R., Aoyagi, Y., Murakawa, T. and Kimoto, K. (1999). Effects of angiotensin I-converting enzyme inhibitor from ashitaba (angelica keiskei) on blood pressure of spontaneously hypertensive rats. J. Nutr. Sci. Vitaminol., 45, 375-383.

Takenaka, T., Muryama, T. and Takenaka, Y. (2009). Isolation of nicotianamine from soybean broth and changes in its content in the soybean steaming process, Nippon Shokuhin Kagaku Kogaku Kaishi, 56, 6-13 (in Japanese).

Yanai, H. (2004) 4 step Exel statistic. OSS press. 